\title{
Gestão da biblioteca universitária: análise com base nos indicadores de avaliação do MEC
}

\section{Luiz Cláudio Gomes Maia}

\author{
Doutor em Ciência da Informação e professor do \\ Programa de Pós-Graduação em Sistemas de \\ Informação e Gestão do Conhecimento da \\ Universidade FUMEC
}

Maria De Souza Lima Santos

\begin{abstract}
Mestre em Administração Profissional pela Faculdade de Estudos Administrativos de Minas Gerais (FEAD) Bibliotecária da UFG
\end{abstract}

http://dx.doi.org/10.1590/1981-5344/2079

O objetivo deste artigo é compreender como os gestores do Sistema de Bibliotecas da UFG (Sibi/UFG) utilizam os indicadores de avaliação do MEC durante o processo de aquisição de recursos informacionais. A investigação foi realizada por meio de entrevistas semiestruturadas e analisadas de forma descritiva, por meio de um estudo de caso a partir do qual se buscou interpretar as informações, tendo como base o referencial teórico que norteou o desenvolvimento da pesquisa, com os gestores das bibliotecas e com os bibliotecários gerentes de atendimento. Os resultados apontam que há uma homogeneidade acerca do processo de avaliação e que a biblioteca precisa definir, junto ao corpo docente, e a administração da Instituição, uma Política de Formação de Acervo que deverá orientar o processo de aquisição de materiais bibliográficos nos diversos formatos, tanto para cursos existentes quanto para novos. Contribuindo, dessa forma, para um melhor atendimento às novas diretrizes estabelecidas pelo MEC e, consequentemente, resultando em melhorias para a biblioteca universitária.

Palavras-chave: Bibliotecas

universitárias; Administração; Avaliação. 


\title{
Management of the university library: an analysis based on MEC's evaluation indicators
}

\begin{abstract}
This study aims to analyze how the library directors of one library system in Brazil use the Ministry of Education evaluation indicators during the process of acquiring information resources. The research was carried through semi-structured interviews and analyzed descriptively, through a case study which sought to interpret the information, based on the theoretical framework that guided the development of the research with the library directors and public services librarians. Results show that there is a uniformity in the evaluation process and that the library needs to define, together with the faculty and the Administration of the Institution, a Collection Development Policy that should guide the purchase process of bibliographic materials in various formats for both existing and for new courses. Contributing thus to comply with the new guidelines established by Ministry of Education and hence resulting in improvements to the university library.
\end{abstract}

Keywords: University Libraries; Management; Evaluation.

Recebido em 21.12.2014 Aceito em 05.05.2015

\section{Introdução}

A avaliação do ensino está cada vez mais sendo adotada no ambiente das universidades, fazendo com que essas instituições se estruturem e passem a atender ou a criar novos produtos e serviços com qualidade. Dias Sobrinho (2002) reforça que a avaliação é um instrumento de medida e controle que responde às expectativas de eficiência e produtividade que os Estados controladores têm a respeito da educação superior. Almeida (2000) considera a avaliação como um processo contextualizado no ciclo administrativo, cujas funções têm, no planejamento, o início de quais resultados se deseja atingir. Assim, a avaliação institucional representa a aplicação dessa teoria no ambiente organizacional da universidade e também na biblioteca.

Os processos de avaliação institucional no âmbito das Instituições Ensino Superior (IES) têm despertado, nos profissionais bibliotecários, uma preocupação com a definição de um conjunto de dados estatísticos - 
incluindo tipo, formas de obtenção, métodos e processos de coleta desses dados para fins de avaliação dos serviços prestados pelas bibliotecas universitárias. Afinal, avalia-se com o objetivo de analisar o cumprimento de algo planejado. De acordo com Almeida (2000),

A principal função da avaliação é produzir conhecimentos relativos à unidade de informação, a organização em que esta se situa e a seu ambiente, para servir de subsídio ao planejamento tanto na fase de elaboração do plano, programa ou projeto, quanto na fase de implementação das ações. A avaliação possibilita a escolha certa, ou seja, a correta definição dos objetivos no momento da concepção do plano. $\mathrm{Na}$ implementação do plano, produz informações que contribuem para a maior produtividade e para a melhoria da qualidade. No final do processo, permite comparar resultados esperados e conseguidos, conhecer o nível de satisfação do público-alvo e os efeitos do planejamento na unidade de informação, na organização e no ambiente. (ALMEIDA, 2000, p. 11).

A avaliação das condições de ensino, que têm exigências específicas em relação às bibliotecas, é regulamentada pelo Decreto $n^{0} 5.773$, de 9 de maio de 2006 (BRASIL, 2006), que dispõe sobre a organização do ensino superior, a avaliação de cursos e instituições, entre outras providências.

Os critérios de avaliação utilizados pelo Ministério da Educação (MEC) mostram o quanto esses processos de avaliação devem servir não apenas para identificar problemas, mas também para buscar alternativas de solução. Para Klaes e Pfistcher (1994), a avaliação deve ser entendida como um processo com instrumentos, objetivos, critérios e metodologia previamente definidos e nunca como tendo um fim em si mesmo.

Os bibliotecários, por sua vez, devem estar cientes das exigências do MEC para a composição e atualização dos acervos no que se refere à qualidade e à quantidade mínima de títulos e exemplares. No que diz respeito à quantidade, deve ser determinado um percentual de exemplares destinados à literatura básica e outro para a literatura complementar. A regra diz respeito também à assinatura dos periódicos científicos.

Os três itens que impactam na avaliação da biblioteca junto ao curso estão na dimensão três (infra-estrutura) do instrumento utilizado pelos avaliadores do MEC. São os itens 3.6 Bibliografia Básica, 3.7 Bibliografia Complementar e 3.8 Periódicos especializados. Estes itens são detalhados na seção 4 deste artigo.

A avaliação da biblioteca no contexto da gestão na universidade é de grande importância, pois ela não se resume em apenas quantificar os serviços oferecidos. É preciso mensurar os dados quantificados visando à melhoria da biblioteca para que ela possa atender às necessidades da 
comunidade acadêmica e firmar-se como órgão necessário dentro da universidade.

O objetivo deste artigo é compreender como os gestores do Sistema de Bibliotecas da UFG (Sibi/UFG) utilizam os indicadores de avaliação do MEC durante o processo de aquisição de recursos informacionais além de analisar como os gestores utilizam esse instrumento.

\section{Gestão nas universidades públicas brasileiras}

A trajetória do sistema educacional no Brasil está associada ao tripé herança cultural, evolução econômica e estruturação do poder político do Estado brasileiro. Segundo Alves e Passador (2011), esses três aspectos refletem na educação sob a forma de avanços e retrocessos.

Segundo Malback Neto (2007), a primeira expressão legal de valorização da gestão universitária é de 1931, através do Estatuto da Universidade Brasileira, durante reforma implementada por Francisco Campos que orientava a estruturação das universidades com padrões determinados pelas políticas públicas. O Governo Federal era o detentor do controle de qualidade da educação superior, fosse ela ministrada em instituição pública ou privada.

A tipologia das IES no Brasil foi redefinida pela LDBEN (Lei $\mathrm{n}^{\circ}$ 9.394/1996) (BRASIL, 1996) e pelos Decretos $n^{\circ} 3.860$, de 2001, e 2.406, de 1997 (BRASIL, 1997; 2001), trazendo inovações para o sistema de ensino superior, principalmente quanto à natureza e depe2006ndência administrativa. A LDBEN introduziu importantes diretrizes no sistema, como as avaliações sistemáticas dos cursos de graduação e das próprias instituições de ensino, que passaram a realizar ou passar por avaliações periódicas que subsidiam os atos autorizativos de cursos - que incluem autorização, reconhecimento e renovação de reconhecimento -, dando transparência aos dados sobre a qualidade da educação superior para a sociedade.

As universidades públicas ocupam posição fundamental no cenário acadêmico nacional, detendo papel estratégico no processo de desenvolvimento científico e tecnológico do País. Elas têm como objetivos principais desenvolver, disseminar e socializar o conhecimento humano. $\mathrm{E}$ a sociedade espera que as universidades contribuam para que o País enfrente com êxito os desafios que lhes são apresentados rumo ao desenvolvimento social, econômico e cultural, de acordo com Soares (2002).

Stallivieri e Marcelino (2008) afirmam, ainda, que a gestão universitária brasileira atravessa um período de intensa profissionalização, envolvendo dimensões de ordem econômica e mercadológica, o que impõe aos seus gestores o conhecimento de uma estrutura normativa mais eficiente e mais voltada para o cidadão - que passa a ser visto como cliente. O processo enfatiza também a eficácia e a economia nos gastos públicos, concebendo, assim, a ideia de que a gestão é importante. Para atender a essa nova demanda, são utilizados instrumentos e padrões de 
desempenho e de qualidade, bem como medidas de avaliação, tendo como objetivo principal o de atingir a excelência nos serviços públicos.

Como em qualquer organização, a universidade requer um planejamento que melhor atenda aos seus objetivos. Dessa forma, Stallivieri e Marcelino (2008) observam que o planejamento deve ser visto como um documento de constantes consultas e norteador do desenvolvimento das atividades da universidade, sendo ainda necessária a delegação de autonomia e responsabilidade relacionados aos investimentos a serem efetuados no processo. Os autores citados ressaltam que a dependência das Instituições Federais de Ensino Superior (IFES) relacionada aos recursos para investimentos ou financiamento é fator responsável pela existência de amarras no que tange à autonomia e gestão universitária quando se fala da rede pública de ensino superior.

Amaral (2003) pontua que é necessário modernizar as instituições. O autor destaca também que a profissionalização da gestão deve estar voltada às necessidades básicas para a sobrevivência das instituições. Nesse contexto, um gestor adequado à pós-modernidade, era da informação e da incerteza, buscará promover um ambiente de trabalho pautado no comprometimento e na integridade.

\section{Gestão nas bibliotecas universitárias}

No Brasil, o marco da biblioteca universitária se deu em 1968, com a Reforma Universitária, que reestruturou o ensino superior, redefiniu seus objetivos e propiciou, de forma indireta, maior racionalidade à biblioteca universitária. As bibliotecas não foram contempladas pela Reforma Universitária; porém, esse documento abriu novos caminhos para elas ao definir as atividades de ensino, pesquisa e extensão. A definição dessas atividades demanda a existência de bibliotecas organizadas para atender a clientela da universidade nos níveis de graduação e de pós-graduação. Ferreira (1980) afirma que:

Assim como a universidade deve estar voltada para as necessidades educacionais, culturais, científicas e tecnológicas do País, as bibliotecas devem trabalhar visando a esses mesmos objetivos, condicionadas que são às finalidades fundamentais da universidade. Por isso, as bibliotecas devem participar ativamente do sistema educacional desenvolvido pela universidade. Do mesmo modo que não há sentido em universidades desvinculadas da realidade sócio-econômica, as bibliotecas universitárias só poderão ter sentido se estiverem em consonância com os programas de ensino e pesquisa das universidades a que pertencem. (FERREIRA, 1980, p. 7).

De maneira semelhante nas questões de cunho administrativo, Lima (1978) contribui afirmando que o planejamento da biblioteca deve ser sistêmico, considerando o ambiente do qual faz parte. O autor defende que não se pode pensar em planejamento de biblioteca universitária sem 
se considerar os planos, objetivos e metas das instituições às quais ela está inserida. No entanto, historicamente não é isso que se verifica. Para Lima (1978),

a falta de objetivos definidos para o ensino universitário provocou, no Brasil, idêntica indefinição dos objetivos de suas bibliotecas. Estatutos e regimentos aludiam, é certo, e sempre de maneira vaga e imprecisa, às finalidades das Instituições e ao papel que a biblioteca deveria desempenhar como suporte às atividades da escola ou faculdade a que pertencia. (LIMA, 1978 , p. 12).

Oliveira (2010) ressalta que a biblioteca universitária deve servir de apoio aos conteúdos ministrados em cada curso oferecido pela instituição na qual está inserida, os quais devem estar devidamente descritos nos Projetos Políticos Pedagógicos (PPC). A biblioteca universitária deve também oferecer suporte à investigação técnico-científica, sempre apoiando o tripé ensino, pesquisa e extensão.

A questão da aquisição de publicações em atendimento aos PPC pelas bibliotecas é vista como um processo difícil, principalmente pelos entraves burocráticos no processo de compra de material bibliográfico. Ferreira (1980) alega que

Pode-se sentir que, de fato, o orçamento é um dos pontos de estrangulamento das bibliotecas universitárias, responsável por muitos de seus problemas de acervo, pessoal, material e equipamento e instalações. Por outro lado, esses orçamentos, muitas vezes, são fragmentados por bibliotecas que terminam sem poder, de fato, realizar algo com verba tão irrisória. Um orçamento global para o sistema bibliotecário de uma universidade, a ser movimentado pela biblioteca central, parece ser a medida mais racional e econômica. Há, inclusive, com respeito a orçamento, outros problemas como fato de algumas bibliotecas não constituírem unidade orçamentária, o que faz com que elas não saibam com quanto podem contar para a sua programação. E também a biblioteca não participa da elaboração do orçamento do programa. (FERREIRA, 1980, p. 75).

Segundo Ramos (1999), a avaliação deve se basear em princípios voltados para a filosofia da qualidade, por meio do diagnóstico da biblioteca, com a identificação de indicadores de avaliação e de qualidade e das ferramentas utilizadas para a gestão da biblioteca universitária em todos os seus aspectos. 


\section{Sistema Nacional de Avaliação da Educação Superior (SINAES)}

A questão da avaliação institucional nas universidades brasileiras foi inicialmente discutida pelo movimento dos docentes, coordenado pela Associação Nacional dos Docentes do Ensino Superior (ANDES), em 1982. Em 1983, surgiu a primeira proposta de avaliação da reforma universitária (PARU), com a concepção de que a avaliação deveria ser utilizada como forma de as IES prestarem contas dos recursos recebidos e justificarem os investimentos aplicados. O Grupo Executivo para a Reformulação da Educação Superior (GERES), criado pelo MEC em 1986, visava a reestruturação do ensino superior e tinha como objetivo dar continuidade às propostas elaboradas pela Comissão Nacional para Reformulação da Educação Superior (CONAES), criada em 1985. O processo de avaliação deveria, segundo o GERES, contemplar duas vertentes básicas: a avaliação do desempenho institucional e a avaliação da qualidade do curso oferecido.

Em 1996, o Governo Federal, em busca do nivelamento da qualidade de oferta da educação superior, instituiu nacionalmente o Exame Nacional de Cursos, popularmente conhecido por Provão. O instrumento servia para avaliar as condições de ensino e também para a avaliação destinada ao credenciamento das IES. O exame foi aplicado no período de 1996 a 2003 aos alunos concluintes dos cursos de graduação. Apesar de gerar polêmicas, o Provão provocou mudanças nas IES, como reformulações em seus currículos e mudanças administrativo-pedagógicas (BRASIL, 2012).

A partir do ano de 2002, foi institucionalizada a visita de uma comissão de avaliadores do MEC às IES, a qual tem por função verificar as condições relacionadas ao ensino, à pesquisa, à extensão, à responsabilidade social, ao desempenho dos alunos, à gestão da instituição, ao corpo docente e às instalações. Os avaliadores são incumbidos de verificar in loco as condições da instituição, avaliando os cursos e autorizando ou não a criação ou continuidade dos mesmos (BRASIL, 2004).

Em 2003, visando contribuir para o aprimoramento da qualidade da educação superior, bem como do sistema educacional como um todo, o governo brasileiro passou a contar com o Sistema Nacional de Avaliação da Educação Superior (SINAES). Criado pela Comissão Nacional de Avaliação da Educação Superior (CONAES), o SINAES foi oficializado pela Lei no 10.861, de 14 de abril de 2004 (BRASIL, 2004), e regulamentado pela Portaria MEC no 2.051, de 9 de julho de 2004 (BRASIL. Ministério da Educação, 2004).

$\mathrm{Na}$ tentativa de buscar cumprir suas finalidades, o SINAES apresenta como princípios fundamentais: responsabilidade social com a qualidade da educação superior; reconhecimento da diversidade do sistema; respeito à identidade, à missão e à história das instituições; 
globalidade, isto é, compreensão de que a instituição deve ser avaliada a partir de um conjunto significativo de indicadores de qualidade, vistos em sua relação orgânica e não de forma isolada; e continuidade do processo avaliativo (BRASIL, 2004).

A avaliação institucional é, atualmente, uma questão de extrema importância e relevância para a educação superior. Ela é considerada estratégica para a gestão institucional, pois os resultados das avaliações permitem aos gestores tomar decisões para alcançar mais qualidade institucional. A melhora institucional requer, contudo, conhecimento e análise da realidade externa e interna da instituição (EYANG, 2004).

\subsection{Indicadores de avaliação do MEC aplicados à biblioteca universitária}

A biblioteca universitária, que se constitui como suporte ao ensino, à pesquisa e à extensão nas universidades, possui a função de prover a infraestrutura bibliográfica, documentária e informacional de apoio às atividades desempenhadas pela universidade. A biblioteca está classificada na dimensão infraestrutura na metodologia do INEP para avaliação dos cursos, como se pode ver na Seção II (Do Credenciamento e Recredenciamento de Instituição de Educação Superior), Subseção I (Das Disposições Gerais) do Decreto $n^{\circ}$ 5.773, de 9 de maio de 2006 (BRASIL, 2006), e mais especificamente no item VII do artigo 16 do mencionado decreto:

[...] VII - infra-estrutura física e instalações acadêmicas, especificando: a) com relação à biblioteca: acervo de livros, periódicos acadêmicos e científicos e assinaturas de revistas e jornais, obras clássicas, dicionários e enciclopédias, formas de atualização e expansão, identificando sua correlação pedagógica com os cursos e programas previstos; vídeos, DVD, CD, CD-ROM e assinaturas eletrônicas; espaço físico para estudos e horário de funcionamento, pessoal técnico administrativo e serviços oferecidos. (BRASIL, 2006).

Para Vergueiro (1989), a política de formação de coleções deverá funcionar como parâmetro que contribuirá para a tomada de decisão dos bibliotecários em relação à escolha do material a ser incorporado ao acervo, seja por aquisição, doação ou por permuta. Nesse sentido, o autor afirma sobre a política de formação de coleções:

Torna público, expressamente, o relacionamento entre o desenvolvimento da coleção e os objetivos da instituição e a esta coleção deve servir, tanto por causa da necessidade de um guia prático na seleção diária de itens, como devido ao fato de ser tal documento uma peça-chave para 0 planejamento em larga escala. (VERGUEIRO, 1989, p. 25). 


\subsection{Indicador Bibliografia Básica}

A literatura básica ou bibliografia básica, como o nome já diz, é imprescindível para que os alunos acompanhem 0 andamento das atividades acadêmicas, ou seja, em resumo, é obrigatória. Está descrita nos planos de ensino e deve fazer parte da coleção de qualquer biblioteca, devendo ser atualizada, adequada, pertinente e com relevância acadêmico-científica.

No instrumento de avaliação o item 3.6 refere-se a Bibliografia Básica na qual para obter conceito 5 (máximo) deve o acervo da bibliografia básica, com no mínimo três títulos por unidade curricular, está disponível na proporção média de um exemplar para menos de 5 vagas anuais pretendidas/autorizadas, de cada uma das unidades curriculares, de todos os cursos que efetivamente utilizam o acervo, além de estar informatizado e tombado junto ao patrimônio da IES.

\subsection{Indicador Bibliografia Complementar}

A biblioteca precisará formar seu acervo também para a bibliografia complementar. Esse acervo é composto por materiais informacionais essenciais à complementação e atualização voltados para a pesquisa e o ensino nas várias áreas do conhecimento $e$ indicados nos planos de ensino. É composto por registro de documentos, livros, inventários, escritos, impressos ou quaisquer gravações que venham a servir como fonte para consulta, organizada pela identificação de cada uma das obras que constitui a bibliografia, por meio de elementos como o autor, o título, o local de edição, a editora e outros de caráter complementar.

No instrumento de avaliação o item 3.7 refere-se a Bibliografia Complementar na qual obtêm-se conceito 5 (máximo) quando o acervo da bibliografia complementar possui, pelo menos, cinco títulos por unidade curricular, com dois exemplares de cada título ou com acesso virtual.

\subsection{Indicador Periódicos Especializados}

São revistas especializadas, indexadas e correntes, sob a forma impressa ou virtual. As revistas de cunho científico contêm artigos que foram submetidos a revisões de especialistas, assegurando que esses artigos estão dentro dos padrões de qualidade e validade da publicação.

No instrumento de avaliação o item 3.8 refere-se aos Periódicos Especializados e para obter o conceito máximo deve possuir assinatura/acesso de periódicos especializados, indexados e correntes, sob a forma impressa ou virtual, maior ou igual a 20 títulos distribuídos entre as principais áreas do curso, a maioria deles com acervo atualizado em relação aos últimos 3 anos.

Para fins de reconhecimento e renovação de reconhecimento, prevalecem os conceitos que variam de 1 (um) a 5 (cinco) para todos os indicadores. 


\section{Métodos}

Esta é uma investigação realizada por meio de uma abordagem qualitativa e descritiva onde pretendeu-se descrever, por meio de um estudo de caso, a percepção e a contribuição de cada um dos participantes envolvidos no processo de gestão da biblioteca em atendimento ao processo avaliativo pelo MEC.

Foi utilizada uma amostragem não probabilística. A seleção do caso foi definida pelo critério de acessibilidade, pelo fato dos pesquisadores desenvolverem suas atividades profissionais no ambiente da pesquisa e por acompanhar tanto o processo de compra de acervo quanto o processo de avaliação pelo MEC.

A referida pesquisa foi realizada no ambiente da Biblioteca Central (BC) e também nas bibliotecas setoriais do Campus 1 e na Faculdade de Letras, sendo estas também em Goiânia. As demais setoriais estão nos campi de Catalão, Goiás e Jataí, onde há duas unidades, Riachuelo e Jatobá.

As entrevistas foram realizadas com 12 (doze) indivíduos, sendo 6 (seis) diretores de bibliotecas e 6 (seis) gerentes de atendimento escolhidos por acessibilidade. Como instrumentos de coleta de dados foram utilizados: a pesquisa bibliográfica e a entrevista semiestruturada com os gestores e gerentes de atendimento envolvidos com a gestão da biblioteca.

A pesquisa bibliográfica foi utilizada para a fundamentação da teoria metodológica do trabalho e também em atendimento ao objetivo específico de se identificar a legislação de avaliação do MEC aplicável à biblioteca universitária. A entrevista semiestruturada foi utilizada para a coleta de dados qualitativos, foi realizada uma entrevista com os sujeitos participantes da pesquisa: bibliotecários (gestores e gerentes). O roteiro da entrevista semiestruturada foi composto por dez perguntas básicas, a fim de se garantir a cobertura de todos os pressupostos em estudo.

O tratamento dos dados da entrevista foi realizado de forma qualitativa, por meio da análise, pela vivência do observador no ambiente da pesquisa e pelas revisões das informações coletadas. O tratamento dos depoimentos dos entrevistados constou de três etapas: a transcrição das entrevistas de forma fidedigna, a agregação dos dados, que foi o conjunto de respostas, e a síntese. A agregação foi desenvolvida a partir do conjunto das respostas, ou seja, a cada pergunta do roteiro de coleta de dados foram agregadas as respostas dadas pelos entrevistados. A análise constituiu na filtragem das percepções mais significativas dentro do enfoque estudado e, também, das exceções identificadas. Seguiu-se uma análise descritiva, em que se buscou interpretar as informações tendo como base o referencial teórico que norteou o desenvolvimento da presente pesquisa. 
Segundo Bogdan e Biklen (2010), a entrevista é utilizada para recolher dados descritivos na linguagem do próprio sujeito. Dessa forma, o roteiro da entrevista foi elaborado com base no referencial teórico. As questões que abordam a interação biblioteca e unidade acadêmica foram elaboradas de acordo com a dissertação de Oliveira (2010).

As categorias de análise previamente definidas são: 1- instrumento de avaliação e a gestão da biblioteca; 2- interação biblioteca e unidade acadêmica; 3- formação e atualização do acervo em atendimento ao PPC e instrumento de avaliação; 4- recurso financeiro; 5- divulgação.

\section{Apresentação e análise dos dados}

Os tópicos apresentados a seguir referem-se às percepções que os gestores bibliotecários entrevistados possuem sobre o instrumento de avaliação do MEC, bem como a sua relação com a gestão da biblioteca universitária relacionada às atividades de ensino e pesquisa. Buscou-se, nas entrevistas, perceber o entendimento e a importância que os gestores têm do processo de avaliação externa das bibliotecas universitárias. Também suas opiniões a respeito da ideia de o processo de avaliação ser um instrumento de gestão e, levando em conta que a biblioteca é um órgão de informação, em quais aspectos relacionados ao ensino e à pesquisa ela possa contribuir.

Categoria 1: Do conhecimento do Instrumento de Avaliação e do processo de avaliação da biblioteca.

O processo de avaliação é um procedimento necessário e importante para a biblioteca universitária, pois ele contribui na pontuação do curso junto ao MEC. Sobre o atual instrumento de avaliação que é apresentado, ele se pauta exclusivamente por procedimento quantitativo, demonstrando o caráter regulador do mesmo e não traduzindo em si as reais necessidades e carências da biblioteca universitária. Os resultados advindos dos processos avaliativos devem propiciar análises e mudanças efetivas nas bibliotecas.

Constata-se que todos os gestores entrevistados da amostra, doze (12) ao total, conhecem o instrumento de avaliação do MEC e acreditam que, mesmo sendo uma avaliação de caráter quantitativo, ela é de suma importância para o processo de avaliação da biblioteca. O recorte de depoimentos a seguir ilustra esta percepção:

Conheço os instrumentos e os considero extremamente relevantes para a avaliação da biblioteca universitária, especialmente porque servem como norteadores do processo de desenvolvimento de coleções. (GESTOR 1)

As opiniões dos gestores corroboram a visão de Ramos (1999), o qual comenta que a avaliação deve se basear em princípios voltados para 
a filosofia da qualidade, com a identificação de indicadores de avaliação enquanto ferramenta de gestão utilizada. Tais opiniões mostram ainda que o instrumento de avaliação é um documento norteador para o processo de formação e desenvolvimento de coleções da biblioteca universitária. Conforme mencionado antes, Vergueiro (1989) reforça que, para a formação do acervo, seja por aquisição, doação ou permuta, é necessário haver um parâmetro norteado para a tomada de decisões nas bibliotecas.

Categoria 2: Da formação e atualização do acervo em atendimento ao instrumento de avaliação.

Sobre essa questão, busca-se verificar a percepção dos gestores entrevistados sobre o fato de a biblioteca orientar-se ou não pelos projetos pedagógicos ou planos de ensino dos cursos de graduação, utilizando-os como fonte de informação para a formação e atualização dos acervos da Sibi/UFG em atendimento ao instrumento de avaliação. A seguir, é apresentado um depoimento acerca desse item.

Sim, a biblioteca deve estar sempre informada sobre os PPC dos cursos de graduação como fonte de informação para a formação e atualização dos acervos do Sibi/UFG, já que seu propósito primeiro é servir de apoio ao tripé de ensino, pesquisa e extensão. A biblioteca deve conhecer bem o público a que se destina e suas necessidades para buscar suprir informacionalmente esse público. (GESTOR 2)

No exemplo apresentado, percebe-se a importância do PPC, bem como seu impacto na estrutura do instrumento de avaliação, que, segundo o INEP (BRASIL, 2012), é o documento orientador de um curso que traduz as políticas acadêmicas institucionais com base nas diretrizes curriculares nacionais (DCNs), sendo composto pela estrutura e conteúdo curricular, ementário, bibliografia básica e complementar, recursos materiais, laboratório e infraestrutura de apoio ao pleno funcionamento do curso. Oliveira (2002) reforça que a biblioteca universitária deve servir também de apoio aos conteúdos ministrados, devidamente descritos nos PPC, o que respalda as opiniões dos entrevistados.

Por outro lado, durante as entrevistas surgiram algumas opiniões que refletem, também, a dificuldade de alguns gestores em acompanhar as atualizações dos PPC, como no recorte a seguir.

Sim, mas não somente, pois existe uma grande dificuldade de acessar e atualizar os projetos pedagógicos na dinâmica de aula no contexto institucional. (GESTOR 3)

Essa percepção dos gestores entrevistados reforça a figura do professor coordenador e da importância do NDE. O professor coordenador do NDE deve ser o elo entre a unidade de ensino e a biblioteca, sendo 
ambos corresponsáveis pela alimentação e retroalimentação das bibliografias básicas e complementares e dos periódicos nos PPC.

Categoria 3: Do recurso financeiro.

A respeito dessa questão, busca-se verificar, a partir da percepção dos gestores entrevistados, se eles consideram os recursos financeiros suficientes para a aquisição de material informacional, em atendimento ao instrumento de avaliação. A seguir, é transcrito um dos julgamentos acerca deste item.

Não, ele não é suficiente pela quantidade de cursos e pela recomposição ou formação do acervo pela bibliografia básica. Não é suficiente, precisa de ser muito maior para que a biblioteca mantenha o acervo de todos os cursos pelo menos quatro vezes do que é hoje para cumprir a quantidade solicitada e descrita no instrumento do MEC. (GESTOR 2)

No exemplo apresentado, percebe-se que os gestores entrevistados reconhecem que o valor destinado a cada ano não é suficiente para se realizar a compra do material em atendimento ao instrumento de avaliação do MEC. Essa percepção dos entrevistados reforça a visão de Ferreira (1980) de que a questão da aquisição de publicações em atendimento aos projetos pedagógicos pelas bibliotecas é um processo difícil por haver entraves burocráticos na compra de material bibliográfico. $E$ também pelo fato de que o orçamento é um dos pontos de estrangulamento nas IFEs, responsável por muitos dos problemas nas instituições, entre eles a desatualização de acervos bibliográficos.

O depoimento a seguir reproduz a opinião de dois dos entrevistados, que reconhecem o esforço institucional na ampliação do recurso:

Reconheço o esforço da Instituição em garantir o recurso financeiro para aquisição de material informacional, que a cada ano tem um reajuste, mas ainda não é suficiente para garantir um acervo totalmente adequado. (GESTOR 4)

Um dos entrevistados afirma que há, sim, um aumento nos recursos; porém, a Universidade não possui uma preocupação sistematizada em primeiro criar a estrutura necessária para depois criar um novo curso.

Não, apesar dos investimentos sistemáticos anuais desde 2000, pois se verifica que a Universidade, na sua história, ao longo dos últimos anos, aprovou diversos cursos sem estrutura adequada para o seu funcionamento. Houve uma inversão, primeiro aprova e depois organiza a estrutura, fato 
que traz grandes dificuldades para o ensino e também grandes problemas administrativos. (GESTOR 5)

Stallivieri e Marcelino (2008) observam que a universidade, como qualquer outra organização, requer um planejamento que atenda melhor aos seus objetivos diversos e difusos, pois o planejamento deve ser um documento norteador do desenvolvimento das atividades da universidade. Esse pensamento é reforçado por mais um dos gestores entrevistados, que afirma:

A Universidade deve dar um suporte melhor para os cursos novos, destinar um recurso maior; o que a gente percebe é que se cria o curso para depois ver o que é preciso para ele funcionar e como a biblioteca é avaliada. Chegam aqui tanto o professor quanto o aluno e não temos o básico para atendêlos, depois vem a avaliação e, portanto, somos mal avaliados, porque o que faltou foi o planejamento. (GESTOR 6)

Categoria 4: Do papel da biblioteca universitária no desempenho dos cursos.

Nessa categoria, é abordada a relação entre o papel da biblioteca, o desempenho dos cursos e também em quais aspectos ela, a biblioteca, pode contribuir. Constatou-se que as opiniões foram praticamente homogêneas no sentido de que se referem ao apoio da biblioteca ao ensino, à pesquisa e à extensão. Tais opiniões podem ser observadas e resumidas no depoimento abaixo.

A função primordial de uma biblioteca universitária é dar suporte ao tripé da instituição, que é o ensino, a pesquisa e a extensão. Dessa forma, a biblioteca tem um importante papel nos cursos oferecidos pela instituição, pois ela será o suporte acadêmico para que os alunos façam suas pesquisas, realizem seus estudos de forma sistemática. Daí vem toda a importância de se ter acervos condizentes com a realidade dos cursos, com que é ensinado e pedido em pesquisa pelos docentes. (GESTOR 2)

Quanto aos aspectos em que a biblioteca contribui, as respostas foram variadas em diferentes segmentos. Confira a seguir uma delas.

Acho que a biblioteca pode contribuir capacitando os alunos no uso dos recursos informacionais disponíveis, como cursos e treinamentos como, por exemplo: treinamentos do Portal da Capes, curso de normalização bibliográfica, entre outros. (GESTOR 7) 
Em ambos os aspectos, percebe-se a importância da biblioteca em parceria com os cursos. Lubisco (2009) ressalta que as bibliotecas universitárias são importantes no processo de formação dos indivíduos, pois elas assumem o papel de mediadores entre as novas competências que são desenvolvidas no ambiente acadêmico e também atuam a favor do conhecimento que a comunidade acadêmica demanda. Ainda de acordo com a autora citada, as bibliotecas devem oferecer suporte à investigação técnico-científica, apoiando o tripé ensino, pesquisa e extensão.

Categoria 5: Repasse, pela Universidade, do relatório final da avaliação de comissão do MEC à biblioteca após a visita.

Um dos pontos importantes no processo de avaliação nas instituições de ensino é o relatório final enviado pelos avaliadores à universidade após a visita in loco. Nele, estão as percepções dos avaliadores sobre as dimensões avaliadas e os conceitos obtidos. Nesta questão pode-se observar, diante da maioria das respostas, que a UFG não repassa o relatório para a biblioteca. Esta lacuna leva ao pensamento de que a Instituição não considera que a biblioteca possa contribuir de forma igual e decisiva, em relação a outras dimensões avaliadas, com o processo de avaliação da qualidade da Instituição. A seguir, alguns depoimentos colhidos nas entrevistas.

Não tenho conhecimento desse relatório final. Acredito que a partir desse relatório, a biblioteca poderia compartilhar com as coordenações de cursos quanto aos apontamentos referentes à composição do acervo e formular estratégias para resolver as falhas. (GESTOR 8)

Constatou-se que os gestores de duas das bibliotecas setoriais solicitaram o relatório à Universidade para fazer uma avaliação do que foi pontuado pelos avaliadores, conforme mostra a declaração a seguir:

Os relatórios são repassados pelos coordenadores quando a biblioteca solicita. O diálogo acontece nas vésperas das avaliações. Quando algum curso é mal avaliado, a coordenação do curso e a direção da unidade tomam as providências necessárias para que a situação seja readequada. A biblioteca faz a intervenção sempre que essa situação acontece para acompanhar e orientar algumas ações. (GESTOR 3)

Pelos depoimentos expostos, percebe-se que a interação entre a biblioteca e os coordenadores de cursos é importante. Mas o que se percebe no todo é que há uma lacuna, pois não é praxe sociabilizar o resultado das avaliações com a biblioteca. Entende-se que o processo da 
avaliação perpassa pela posterior reflexão sobre os resultados avaliados. E que o relatório final permite que se analise o que deve e pode ser melhorado, possibilitando também propor mudanças efetivas na gestão da biblioteca.

Para Amorim (1992), a instituição de ensino deve instituir a cultura da avaliação, envolvendo coletivamente todos os agentes inseridos no processo, o que não está sendo feito na UFG, como se percebe a partir das entrevistas coletadas.

\section{Considerações Finais}

Partiu-se do princípio de que os instrumentos de avaliação do MEC são importantes na gestão da biblioteca universitária face ao processo de aquisição de material informacional no intuito de corresponder às necessidades dos alunos dos cursos de graduação da UFG. O foco da pesquisa desenvolvida foi o estudo de caso no Sistema de Bibliotecas da UFG, que reúne algumas das principais bibliotecas universitárias da região, sendo referência no Estado de Goiás.

A definição pelos gestores de biblioteca de diferentes campi da Universidade deu um caráter especial à pesquisa, evidenciando a percepção e a vivência de cada participante nas entrevistas. A percepção de cada gestor foi importante pelo nível de envolvimento com a gestão da biblioteca e com o tema da avaliação, sendo estes também responsáveis diretamente pelo acompanhamento dos avaliadores do MEC, por ocasião da visita in loco.

As entrevistas realizadas com os diferentes gestores envolvidos com a administração das bibliotecas, e também com o processo de avaliação, foram imprescindíveis. Elas permitiram que se verificassem os diferentes níveis de percepção sobre os temas abordados, o que proporcionou maior abrangência a este estudo.

A análise das diferentes dificuldades detectadas nas entrevistas sobre os aspectos organizacionais relacionados aos processos de avaliação fornece subsídios para se propor ações articuladas entre a biblioteca, os coordenadores de cursos e a UFG, de forma institucionalizada.

Um dos aspectos percebidos e manifestados pelos entrevistados foi a importância e a necessidade que tem o gestor da biblioteca de conhecer o instrumento de avaliação e tê-lo como ferramenta para a gestão na Universidade, principalmente pelo fato de que a biblioteca está incluída no contexto da avaliação institucional. Tal inclusão perpassa a ideia de a biblioteca atender às necessidades dos cursos da Instituição e que a sua avaliação tem impacto em outros importantes indicadores, como o PDI, o PPC e o NDE. Dessa forma, a avaliação se constitui em uma ferramenta capaz de propiciar melhorias para a biblioteca, sendo de grande importância no momento de negociações com a administração superior para novos investimentos.

No tocante ao aspecto da formação e atualização do acervo, em atendimento tanto ao instrumento de avaliação quanto ao projeto pedagógico do curso, verificou-se que tais processos são muito 
importantes para as bibliotecas e para a Instituição. Tal percepção é compartilhada com todos os 12 (doze) gestores entrevistados, que reconhecem que a biblioteca possui um importante papel na condição de recurso pedagógico. E que é seu papel oferecer a quantidade necessária da bibliografia básica, a bibliografia complementar, a assinatura de periódicos e também o acervo virtual aos cursos ministrados. Outro aspecto a ser considerado, diante da diversidade de cursos e da dimensão da Universidade, é o desafio da biblioteca de possuir os PPC. E mais: atualizados. Por outro lado, a UFG deve colaborar criando uma ferramenta capaz de facilitar, dar acesso e permitir interação, a todos os interessados, aos PPC e às bibliografias descritas em seus planos.

A questão da interação entre biblioteca e unidade de ensino é fundamental e a ideia foi corroborada na pesquisa pelas manifestações dos entrevistados. A biblioteca deve trabalhar de forma integrada com os setores pedagógicos, coordenadores de cursos, conselheiros da biblioteca, professores e alunos, possibilitando, assim, a disponibilização de um acervo em quantidade suficiente e com qualidade. Para que isso se concretize, é preciso que o bibliotecário seja o elo entre todos os atores envolvidos no processo pedagógico. É preciso que a biblioteca esteja sempre em conexão com os atores pedagógicos, evitando, assim, que o contato entre eles ocorra somente no período de distribuição do recurso ou no período da avaliação dos cursos.

Outro aspecto a ser considerado é o recurso financeiro, reconhecido institucionalmente como não é suficiente para atender à demanda real dos cursos por material informacional. Apesar de o valor ser acrescido a cada ano, tal prática não consegue atender ao que está proposto no instrumento de avaliação. Um dos motivos é a própria dinâmica aplicada pela Instituição no processo de ampliar a quantidade de vagas e/ou criar novos cursos. Apesar da iniciativa de incrementar o recurso financeiro para os cursos a serem avaliados, ele é insuficiente para atender a todas as disciplinas e a quantidade exigida. É imperativo que a Instituição invista, em primeiro lugar, na montagem da estrutura adequada para, depois, dar andamento à criação de novos cursos e/ou ampliar o número de vagas em cursos já existentes.

Em relação ao processo de divulgação de ações para o recebimento dos avaliadores e ao resultado do processo avaliativo pela comissão de avaliadores, percebe-se que não há uma sistemática na atitude da Instituição para com a biblioteca. Considera-se que é de suma importância que a biblioteca seja inserida nas discussões e ações desenvolvidas pela Universidade, em particular as que envolvem assuntos relativos à biblioteca.

Finalizando, pode-se dizer que este trabalho atingiu o objetivo proposto. A partir das entrevistas realizadas com os gestores das diferentes bibliotecas do Sibi/UFG, foi possível a análise das categorias propostas. Também foi confirmado que as categorias eleitas para a pesquisa levantaram os pontos mais importantes, quando se fala em avaliação das bibliotecas, e que esses pontos podem ser trabalhados 
institucionalmente para uma melhor avaliação da biblioteca visando a atender melhor o que é solicitado no instrumento de avaliação do MEC.

O estudo permitiu também observar, de perto e detalhadamente, todos os aspectos do processo avaliativo, tanto no contexto da biblioteca quanto da Universidade como um todo, o que possibilitou verificar que a cultura da avaliação permeia a Instituição como um todo e que pode contribuir para a qualidade do ensino e, consequentemente, para a Universidade.

Espera-se mostrar, com os resultados desta pesquisa, que os critérios de avaliação do MEC devem servir não apenas para identificar problemas, mas para ir além, possibilitando que os gestores das IES e os profissionais bibliotecários possam elaborar estratégias visando a aquisição e atualização das bibliografias básicas e complementares dos cursos ministrados na Universidade Federal de Goiás. Proporcionando, assim, a criação de um acervo bibliográfico de excelente qualidade, que atenda efetivamente aos projetos pedagógicos e às necessidades informacionais de toda a comunidade acadêmica.

Um dos fatores observados durante a pesquisa foi a necessidade de se estabelecer uma parceria entre o órgão biblioteca, os coordenadores de cursos e a Instituição objetivando viabilizar um sistema de informação gerencial capaz de agregar e sociabilizar todas as informações dos PPC e das bibliografias básicas e complementares. Recomenda-se, também, que as bibliotecas universitárias procedam à avaliação de sua coleção, em atendimento ao instrumento de avaliação e ao PPC dos cursos. Outra recomendação é que sejam realizadas reuniões periódicas nas unidades acadêmicas, no intuito de firmar, onde houver, ou fortalecer a parceria entre os atores do processo pedagógico.

Como este trabalho não é um fim em si mesmo, e não tem a pretensão de dar a palavra final em nenhum dos assuntos abordados, sugere-se ainda que o estudo aqui proposto seja ampliado. Ou seja, que a pesquisa seja realizada também nas bibliotecas universitárias pertencentes às instituições privadas da região com a finalidade de verificar as práticas e estratégias adotadas por elas.

\section{Referências}

ALMEIDA, M. C. B. Planejamento de bibliotecas e serviços de informação. Brasília, DF: Briquet de Lemos Livros, 2000.

ALVES, T.; PASSADOR, C. S. Educação pública no Brasil: condições de oferta, nível socioeconômico dos alunos e avaliação. São Paulo: Annablume; Brasília: Capes, Inep, 2011.

AMARAL, N. C. A gestão das instituições de ensino superior: o foco do financiamento. In: DOURADO, L. F.; CATANI, A. M.; OLIVEIRA, J. F. (Orgs.). Políticas e gestão da educação superior: transformações recentes e debates atuais. São Paulo: Xamã, 2003. p. 219-239. 
AMORIM, A. Avaliação institucional da universidade. São Paulo: Cortez, 1992.

BOGDAN, R.; BIKLEN, S. Investigação qualitativa em educação: uma introdução à teoria e aos métodos. São Paulo: Porto Editor, 2010.

BRASIL. Presidência da República. Decreto $n^{\circ} 5.773$, de 9 de maio de 2006. Dispõe sobre o exercício das funções de regulação, supervisão e avaliação de instituições de educação superior e cursos superiores de graduação e sequenciais no sistema federal de ensino. 2006. Disponível em: <http://www.planalto.gov.br>. Acesso em: 4 fev. 2011.

BRASIL, Presidência da República. Lei n 9.394, de 1996. Disponível em: <http://www.planalto.gov.br/ccivil_03/leis/l9394.htm>. Acesso em: 28 mai. 2015.

BRASIL, Presidência da República. Decreto 3.860, de 2001. Disponível em: < http://www.planalto.gov.br/ccivil_03/decreto/2001/D3860.htm> Acesso em: 28 mai. 2015.

BRASIL, Ministério da Educação. Decreto 2.406, de 1997. Disponível em: < http://portal.mec.gov.br/setec/arquivos/pdf/dec2406.pdf> Acesso em: 28 mai. 2015.

BRASIL . Sistema Nacional de Avaliação da Educação Superior - SINAES. Lei $\mathrm{n}^{\circ}$ 10.861/2004. Brasília, DF: MEC, 2004.

BRASIL . Ministério da Educação. Instituto Nacional de Estudos e Pesquisas Educacionais Anísio Teixeira - INEP - DAES - SINAES. Instrumento de avaliação de cursos de graduação presencial e a distância. Brasília: MEC, 2012. Disponível em: <http://www.inep.gov.br/instrumentos/manuais>. Acesso em: 25 abr. 2012.

DIAS SOBRINHO, J. Avaliação e educação: técnica e ética. In: DIAS SOBRINHO, J.; RISTOFF, D. (Orgs.). Avaliação democrática: para uma universidade cidadã. Florianópolis: Insular, 2002. p. 37-68.

EYANG, A. M. A avaliação como estratégia na construção da identidade institucional. Revista da Rede de Avaliação Institucional da Educação Superior - RAIES, Campinas, v. 9, n. 3, p. 152, set. 2004.

FERREIRA, L. A. Bibliotecas universitárias brasileiras: análise de estruturas centralizadas e descentralizadas. São Paulo: Pioneira, 1980. p. 7.

KLAES, R. R.; PFITSCHER, E. F. Ainda e sempre a questão da integração biblioteca e universidade. In: SEMINÁRIO NACIONAL DE BIBLIOTECAS UNIVERSITÁRIAS, 8., 1994, Campinas. Anais... Campinas: UNICAMP, Biblioteca Central, 1994. p. 289-300.

LIMA, E. A biblioteca no ensino superior. Brasília: CAPES, 1978.

LUBISCO, N. M. L. Biblioteca universitária brasileira: instrumento para o seu planejamento e gestão, visando à avaliação do seu desempenho: refere-se ao documento base do seminário da biblioteca universitária 
brasileira, realizado em Salvador de 29 de set a 1 de out. de 2008. Colaboração de Sônia Chagas Vieira. Salvador: EDUFBA, 2009. p. 21-22.

MALBACK NETO, G. Avaliação: instrumento de gestão universitária. São Paulo: Hoper Editora, 2007.

BRASIL. Ministério da Educação. Portaria MEC no 2.051/2004. Brasília, DF: $\quad$ MEC, 2004. Disponível em: <http://portal.mec.gov.br/arquivos/pdf/PORTARIA_2051.pdf> Acesso em: 28 maio. 2015.

OLIVEIRA, N. M. A biblioteca das instituições de ensino superior e os padrões de qualidade do MEC: uma análise preliminar. Perspectiva em Ciência da Informação, Belo Horizonte, v. 7, n. 2, p. 207-221, 2002.

OLIVEIRA, J. G. Processo de avaliação do INEP/MEC de bibliotecas universitárias pertencentes às instituições de educação superior privadas de Belo Horizonte. 2010. 282f. Dissertação (Mestrado em Ciência da Informação) - Universidade Federal de Minas Gerais, Belo Horizonte, 2010. Disponível em: <http://www.bibliotecadigital.ufmg.br/dspace/bitstream/1843/ECID87BKMR/1/disserta_o_vers_o_final.pdf>. Acesso em: 6 set. 2011.

RAMOS, M. E. M. Tecnologia e novas formas de gestão em bibliotecas universitárias. Ponta Grossa: UEPG, 1999.

SOARES, M. S. A. A educação superior no Brasil. Brasília: Coordenação de Aperfeiçoamento de Pessoal de Nível Superior, 2002.

STALLIVIERI, L.; MARCELINO, L. R. Gestão e liderança universitária. Caxias do Sul: EDUCS, 2008.

VERGUEIRO, W. Desenvolvimento de coleções. São Paulo: Polis; APB, 1989. 